\title{
(息)
}

Citation:

Wood, E and Thomas, R (2006) Research note: Measuring cultural values - The case of residents' attitudes to the Saltaire Festival. Tourism Economics, 12 (1). 137 - 145. ISSN 1354-8166 DOI: https://doi.org/10.5367/000000006776387187

Link to Leeds Beckett Repository record:

https://eprints.leedsbeckett.ac.uk/id/eprint/903/

Document Version:

Article (Published Version)

The aim of the Leeds Beckett Repository is to provide open access to our research, as required by funder policies and permitted by publishers and copyright law.

The Leeds Beckett repository holds a wide range of publications, each of which has been checked for copyright and the relevant embargo period has been applied by the Research Services team.

We operate on a standard take-down policy. If you are the author or publisher of an output and you would like it removed from the repository, please contact us and we will investigate on a case-by-case basis.

Each thesis in the repository has been cleared where necessary by the author for third party copyright. If you would like a thesis to be removed from the repository or believe there is an issue with copyright, please contact us on openaccess@leedsbeckett.ac.uk and we will investigate on a case-by-case basis. 


\section{Research note: Measuring cultural values - the case of residents' attitudes to the Saltaire Festival}

\section{EMMA WOOD AND RHODRI THOMAS}

Tourism, H ospitality and Events Small Firms Research Centre (THES), Leeds M etropolitan U niversity, Calverley Street, Leeds LS1 3HE, UK. Te: +44 113283 3462. Fax: +44

113283 3111. E-mail: ewood@ leedsmet.ac.uk; r.thomas@leedsmet.ac.uk.

This research note discusses the findings and methodological issues arising from a cultural values survey of residents, particularly in relation to civic pride. In addition to offering insights to the particular case - the Saltaire Festival in the north of England - it provides an approach that might be used elsewhere.

K eywords: events; cultural values; community; Sal taire Festival

Local economic development agencies are increasingly turning to events as a means of enhancing local economic development (Thomas and Wood, 2003). There is evidence - albeit piecemeal - that the justification for public expenditure on such events also tends to include references to less tangible notions such as civic pride and social cohesion. $\mathrm{N}$ evertheless, in practice spending on civic events is easier to justify if the case is made for a positive impact on the economy, for, as H ughes (1999, p 122) puts it, 'the disbursement of the public's taxes on "partying" has drawn its critics'.

Yet, previous research undertaken by the authors on behalf of local authorities in the north of England (W ood, 2005; Thomas and W ood, 2004) has shown that the social benefits of local authority funded events are likely to outweigh the economic benefits. It is, therefore, desirable that the evaluation of the impacts of events should incorporate data relating to non-economic impacts. Though a strong case may be made for the appropriateness of qualitative methods of assessment in a climate in which 'hard' evidence is particularly valued, the use of suitable quantitative methods is likely to carry more weight with policy makers and those responsible for reviewing public expenditure of this kind.

Although there has been research into the economic impacts of events and some studies have developed frameworks for measuring aspects of the social consequences (for example, Fredline and Faulkner, 2000), there has been little discussion of methods for measuring cultural values such as civic pride, sense of place and social belonging. These are the focus of the research reported here. 
The survey of residents' attitudes discussed below was undertaken in Saltaire, West Yorkshire, during the summer and autumn of 2003. Saltaire is a model industrial village that has been inscribed by UNESCO as a world heritage site. The Saltaire Festival, which attracts some 20,000 visitors, is organized under the auspices of the Sal taire Village Society (SVS) rather than the local authority, though the latter now provides funding. SVS was formed by residents in the early 1980s to oppose a road-building scheme and, inter alia, to '... secure the preservation (of the village)... to educate the public... to promote the interests of the inhabitants' (SVS, 1994, p 1). Saltaire thus provides an interesting case study because of the residents' apparent attachment to the locality.

\section{Methodological issues}

The research sought to identify residents' 'feelings about Saltaire'. In order to quantify this, a multi-item scale was developed. An item pool was generated using previous, mainly qualitative research. The items were based on adjectives used to describe Saltaire, expressed as a simple statement. A five-point Likert scale was then selected for ease of response and analysis. The initial item pool consisted of twenty-seven statements which were evaluated by an expert panel (local authority personnel, community members and academics), resulting in eight positive and eight negative statements (see A ppendix).

Once a measure for attitudes to Saltaire had been developed, it was decided that it should be applied over predetermined time intervals to measure changes in the construct. Similar repeated evaluation methods have been used in earlier studies (Mihalik and Simonetta, 1998; Ritchie and Smith, 1991).

Clearly, there are many uncontrollable environmental and individual factors that could have an impact on a person's attitudes to an area; for example, weather, mood, press coverage, etc. In order to measure, as far as possible, the changes due to the event being studied, the survey measured attitude levels several weeks before the event and then immediately afterwards. Local media were also monitored during these periods to identify other potential influences on the findings.

\section{Sampling method and survey administration}

Sample sizes for the survey were determined by various factors. Initially it was hoped that a probability sample could be undertaken using a 95\% confidence level with a $5 \%$ margin of error calculated assuming a 'worst-case' proportional split of $P=0.5$. This gave a total sample size of 384. H owever, given the relatively small number of households (estimated at 665 in the Saltaire area), all were included.

Distributing the self-completion questionnaire to all households resulted in a return of 308 before the festival and 241 afterwards. The completed questionnaires were returned using a prepaid envelope.

The response options on the questionnaires were all numerically pre-coded to allow for ease of data entry. The few open questions were entered verbatim and coded by the researcher where necessary. 


\section{Assessment of the scale}

An evaluation of the validity and reliability of the scale was undertaken using the techniques suggested by Churchill (1979) applied to the Saltaire data. The checks were completed using the full sample from the two attitude surveys, a total of 549 responses.

\section{Construct validity}

Tests were made to verify that the construct being measured was actually 'feelings about Saltaire'. The first test was to check for face validity using a panel to evaluate the items to see if they 'looked' like suitable measures. The second method was to use the coded answers to the open question 'briefly describe how you feel about Saltaire' and check for any correlation between this and the total multi-item scale score. The answers were coded using the classifications 'very positive', 'positive', 'neutral', 'negative' and 'very negative'. The correlation coefficient was calculated as 0.484 . This shows a strong positive correlation without being so close as to suggest that the multi-item scale is superfluous (Churchill, 1979).

\section{Content validity}

To assess how well the items in the scale measure the construct in question, the inter-item correlations were investigated. The average of all the inter-item correlations was 0.351 . This is acceptable and above the exemplary level of 0.3 (Bearden et al, 1993).

Reliability was measured through equivalence (internal consistency of the set of items) using coefficient alpha:

$\begin{aligned} \text { Coefficient al pha }= & \left\{\begin{array}{l}\text { No of items } \\ \frac{-}{\text { No of items- }-}--\overline{1}\end{array}\right\} \times 1- \\ & \left\{\begin{array}{l}\text { total of item variances across subjects } \\ \text { var of total scores across subjects }\end{array}\right\}\end{aligned}$

Coefficient alpha $=16 / 15 \times[1-(14.8 / 88.4)]$

$$
=0.89
$$

The alpha coefficient of 0.89 shows very good internal consistency in the scale and is well within the range viewed as exemplary $(0.6$ and above is acceptable and 0.8 and above exemplary) (Bearden et al, 1993). The scale was reliable and appears to be valid given the above tests.

The validity of the scale items (Table 1) was checked using inter-item correlations. All items had exemplary correlations (above 0.3) except for item 0 , 'Saltaire is supportive', which had a lower but acceptable correlation of 0.286 , and item D, 'Saltaire is trendy', which had a low correlation of 0.164 . Removing item $D$ improved the total inter-item correlation from 0.351 to 0.378 . The removal of item 0 improved this further to 0.394 . These items were therefore removed from the data before further analysis was undertaken. Coefficient 
Table 1. Ordered inter-item correlations.

Saltaire...

A. is a good place to live

I. is declining

L. is depressing

C. is boring

B. is thriving

J. is exciting

G. is improving

F. is poor

$\mathrm{N}$. is unattractive

$\mathrm{H}$. is prosperous

E. is ordinary

$\mathrm{K}$. is unwel coming

$P . \quad$ is unfriendly

$M$. has a strong sense of community

0 . is supportive

D. is trendy

A ll items average correl ation
All scale items

0.41

0.40

0.40

0.40

0.39

0.38

0.37

0.37

0.37

0.36

0.34

0.33

0.33

0.32

0.29

0.16

0.35
Item D

removed

0.43

0.42

0.42

0.41

0.40

0.39

0.39

0.38

0.38

0.37

0.34

0.35

0.35

0.33

0.29

0.38
Items D \& 0 removed

0.44

0.43

0.44

0.42

0.41

0.40

0.39

0.39

0.40

0.37

0.35

0.36

0.35

0.31

alpha also improved slightly from 0.89 to 0.90 with items $D$ and 0 removed despite the sensitivity of coefficient alpha to the number of items in the scale.

The analysis of the survey findings was, therefore, undertaken using an amended scale which omitted the responses to the statements 'Saltaire is supportive' and 'Saltaire is trendy'.

\section{Residents' attitudes to Saltaire}

The results of the two surveys were analysed using a number of statistical techniques. First, a z-test was undertaken to see whether or not there was a significant difference between the 'civic pride' scores before and after the festival (see Table 2). The mean figures for before and after the festival indicate that attitudes towards Saltaire became more negative after the festival. H owever, the $p$-value resulting from the $z$-test is 0.08 , which is greater than the required level of significance (0.05). This therefore suggests that there is insufficient evidence

Table 2. z-test of pre- and post-festival total multi-item scale scores.

Total pre

M ean

Observations

$H$ ypothesized mean difference

Z

$\mathrm{P}(\mathrm{Z}<=\mathrm{z})$ two-tail

z critical two-tail
54.26

308

1.751541

0.079853

1.959961
Total post

52.98

241 
Table 3. Classification of total attitude scores.

Pre-festival frequency $\%$ Post-festival frequency $\%$

Positive (score over 51)

N eutral (score 33-51)

N egative (score under 33)

$\begin{array}{rr}218 & 71 \\ 85 & 28 \\ 5 & 2\end{array}$

157

73

11

65

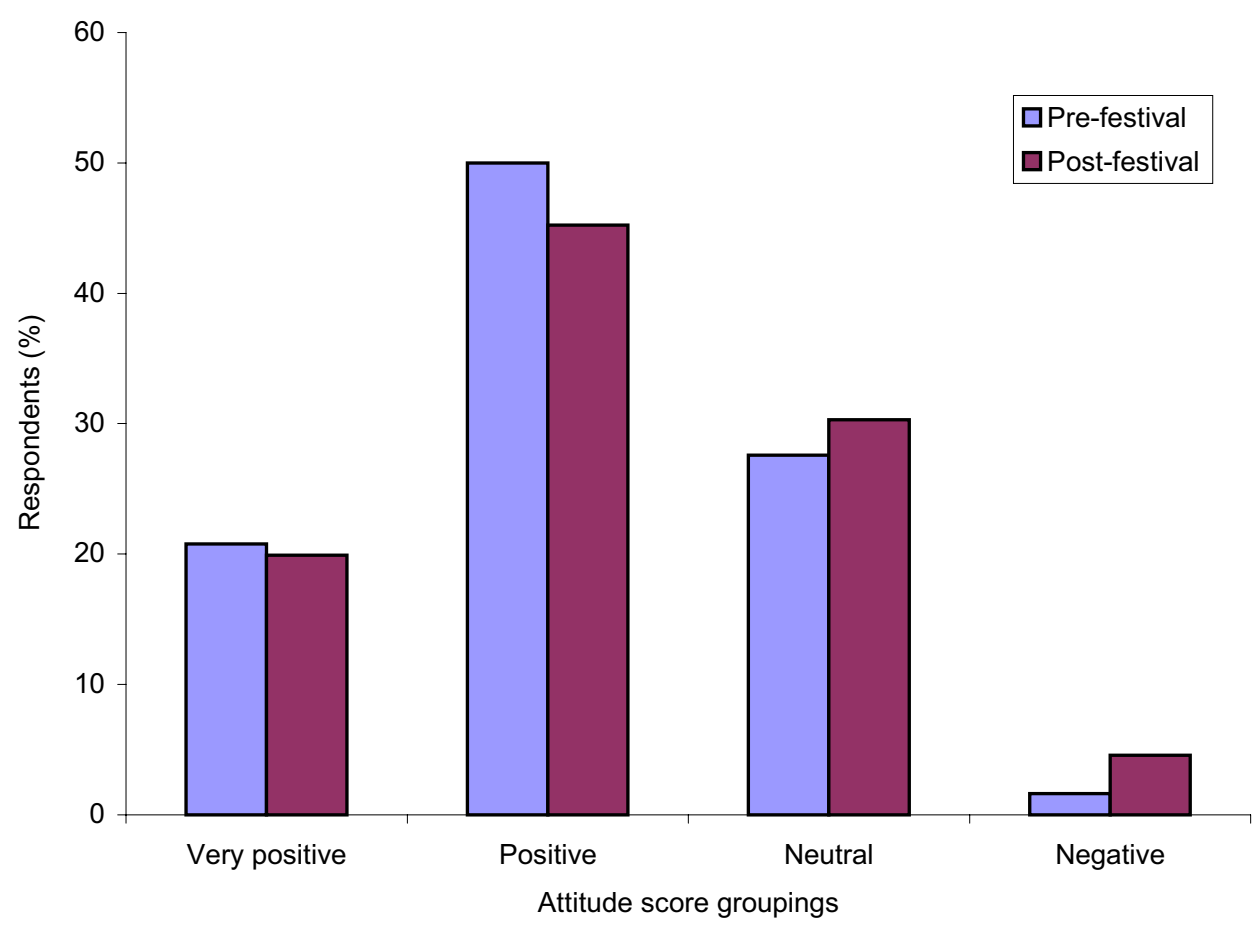

Figure 1. Changes in multi-item attitude scores - feelings about Saltaire.

to reject the hypothesis that the prefestival mean score is equal to the postfestival mean score. The attitudes to Saltaire appear not to have changed significantly after the festival.

Further investigation of the differences between the attitudes before and after the event was undertaken by grouping the total scores into three categories 'positive attitude', 'neutral attitude' and 'negative attitude' (Table 3). Due to the large number of 'positive' responses, this category was further classified to give an additional 'very positive' grouping. The frequency of response for each category was then plotted over the two periods (Figure 1).

These findings suggest that the Saltaire Festival had very little impact on attitudes to the area, as the levels of positive feelings declined slightly but not significantly. However, the number of people with negative feelings about Saltaire more than doubled after the event. There are several possible reasons for this: the festival itself was not viewed as successful or of interest; the residents were not aware of the festival; and/or the levels of positive attitudes 
Table 4. Summary of open statement coding.

Coded response

N egative

N eutral

Positive
Responses (\%)

9

5

86

Table 5. Correlation with attitude score.

Pre-festival

\begin{tabular}{lrr} 
Age & $\mathbf{- 0 . 3 1}$ & $\mathbf{- 0 . 2 4}$ \\
Gender & 0.04 & 0.00 \\
Festival attendance & $\mathbf{0 . 2 4}$ & $\mathbf{0 . 1 5}$ \\
Ethnicity & -0.02 & 0.01 \\
Length of residence & -0.15 & $\mathbf{- 0 . 2 3}$ \\
\hline
\end{tabular}

Post-festival

0.24

0.15

0.01

to the area were already extremely high and, therefore, a substantial improvement could not be achieved.

A nother explanation emerges from further analysis of the qualitative statements about the area (see Table 4). Although these are again overwhelmingly positive, both before and after the festival, the negative statements largely (35\%) relate to 'the over-commercialization' of the area, crime, vandalism and parking problems associated with visiting non-residents, 'too many tourists', and development 'for yuppies by yuppies' not benefiting older residents. The festival may, therefore, have been seen as exacerbating the negative aspects of living in Saltaire by encouraging visitors. The benefits of the 'quiet', 'peaceful', 'small friendly community' aspects of living in Saltaire are frequently mentioned and, again, the festival may have been viewed as detrimental to these.

To check further the validity of the findings, the coded open comments on feelings about the area were also compared before and after the festival (Figure 2). These results reveal only a slight change in attitudes after the event, with the positive comments decreasing from $87 \%$ to $81 \%$ and the negative comments increasing from $5 \%$ to $8 \%$.

M ore detailed analysis was undertaken to see if the characteristics of respondents affected their feelings about Saltaire. As Table 5 suggests, there is a correlation between the intention to attend the festival and the level of civic pride. This is not surprising; it is to be expected that those who enjoy living in Saltaire would participate to some extent in activities associated with it. Gender and ethnicity do not seem to be particularly important variables in explaining the varying attitudes to civic pride, although in relation to the latter there were few returns for minority ethnic groups.

Finally, the findings suggest a correlation between the age of residents and civic pride, with older residents general ly having lower civic pride than younger residents. Similarly, more recent residents are correlated positively with higher levels of civic pride than those who have lived in the area longer.

Though further investigation is required, the data provide tentative support 


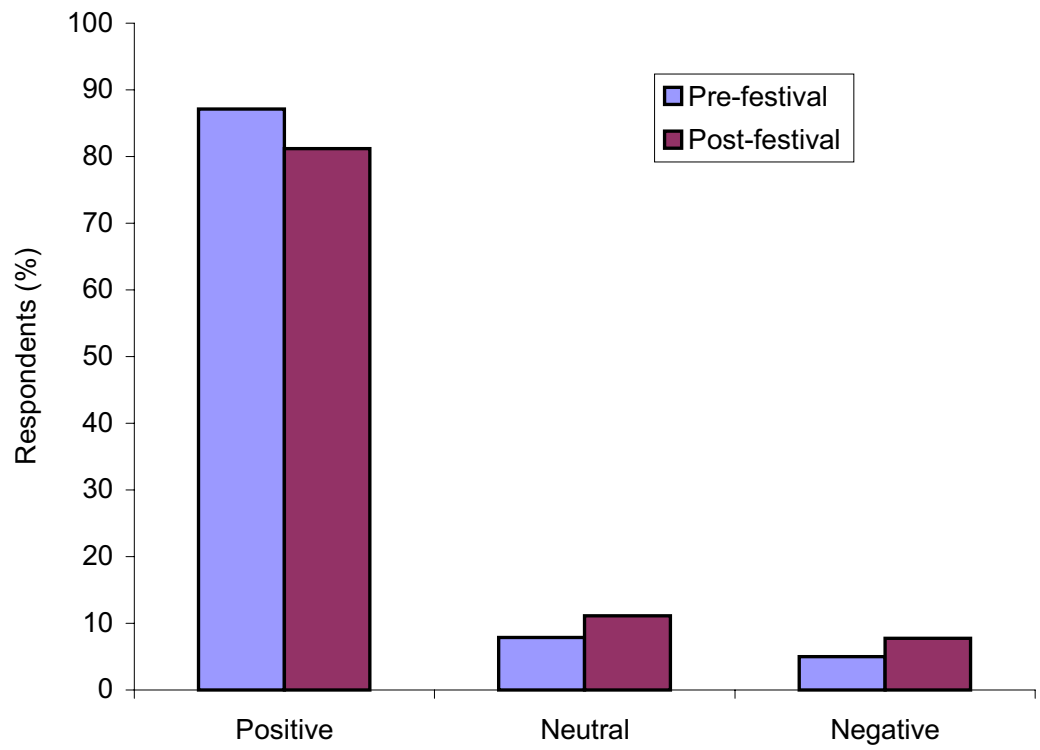

Open statement classification

Figure 2. Changes in nature of open statements - feelings about Saltaire.

for those who point to the 'gentrification' of Saltaire - in which a growing number of single professionals or young couples characterize the local population - as having resulted in a greater sense of 'community'. The extent to which older residents feel excluded from such a 'community' is, however, worthy of further examination.

\section{Concluding comments}

This paper addresses two research aims. The first was to examine the possibility of developing an appropriate instrument for measuring cultural values and to test its utility via a case study. As demonstrated above, the questionnaire does have value and could now be replicated elsewhere. Although the attitude scale was being refined in the course of the study, the results are very encouraging - both in terms of the validity and reliability of the scale and in its usefulness for demonstrating the possible impacts of civic events.

The second aim was to comment on the impact of the Saltaire Festival on local civic pride. Caution has to be exercised because of the limitations of the research - notably in terms of scale - but from this evidence it seems that the festival has little impact on civic pride. Such a finding will no doubt inconvenience those who advocate investment in events on the grounds of its generating additional civic pride. H owever, detractors should note that, given the high levels of pride among residents anyway, a sharp increase was always highly unlikely. Further research in locations with lower levels of civic pride is now required to confirm earlier findings linking civic pride enhancement with community events (Wood, 2005). 


\section{References}

Bearden, W.O., N etemeyer, R.G., and Mobley, M.F. (1993), H andbook of M arketing Scales, Sage, N ewbury Park, CA.

Churchill, G.A. Jr (1979), 'A paradigm for developing better measures of marketing constructs', Journal of M arketing Research, Vol 16, pp 64-73.

Faulkner, B., and Raybould, M. (1995), 'M onitoring visitor expenditure associated with attendance at sporting events: an experimental assessment of the diary and recall methods', $F$ estival $M$ anagement and Event Tourism, Vol 3, pp 73-81.

Fredline, E., and Faulkner, B. (2000), 'Host community reactions: a cluster analysis', A nnals of Tourism Research, Vol 27, No 3, pp 763-784.

H ughes, G. (1999), 'Urban revitalization: the use of festive time strategies', L e sure Studies, Vol 18, pp 119-135.

Mihalik, B.J ., and Simonetta, L. (1998), 'Resident perceptions of the 1996 Summer Olympic Games - Year II', Festival M anagement and Event Tourism, Vol 5, pp 9-19.

Ritchie, J., and Smith, B. (1991), 'The impact of a mega-event on host region awareness: a Iongitudinal study', Journal of Travel Research, Vol 30, No 1, pp 3-10.

SVS (1994), C onstitution, Saltaire Village Society, Saltaire.

Thomas, R., and Wood, E. (2003), 'Events-based tourism: a survey of local authority strategies in the UK', L ocal Governance, Vol 29, No 2, pp 127-136.

Thomas, R., and Wood, E. (2004), 'Community festivals: social benefits or economic returns? The case of Preston M ela', paper presented at 'Engaging with our Communities', Leeds, September.

Wood, E. (2005), 'M easuring the economic and social impacts of local authority events', International Journal of Public Sector Management, Vol 18, No 5, pp 37-53. 


\section{Appendix}

\section{Multi-item scale to measure feelings about Saltaire}

For each of the following statements about Saltaire please state whether you strongly agree, agree, have no opinion, disagree or strongly disagree. (Tick one box only for each statement.)

\begin{tabular}{|l|l|l|l|l|l|}
\hline Saltaire... & $\begin{array}{l}\text { I } \\
\text { strongly } \\
\text { agree }\end{array}$ & I agree & $\begin{array}{l}\text { I'm not } \\
\text { sure/no } \\
\text { opinion }\end{array}$ & $\begin{array}{l}\text { I } \\
\text { disagree }\end{array}$ & $\begin{array}{l}\text { I } \\
\text { strongly } \\
\text { disagree }\end{array}$ \\
\hline is a good place to live & 5 & 4 & 3 & 2 & 1 \\
\hline is thriving & 5 & 4 & 3 & 2 & 1 \\
\hline is boring & 1 & 2 & 3 & 4 & 5 \\
\hline is trendy & 5 & 4 & 3 & 2 & 1 \\
\hline is ordinary & 1 & 2 & 3 & 4 & 5 \\
\hline is poor & 1 & 2 & 3 & 4 & 5 \\
\hline is improving & 5 & 4 & 3 & 2 & 1 \\
\hline is prosperous & 5 & 4 & 3 & 2 & 1 \\
\hline is declining & 1 & 2 & 3 & 4 & 5 \\
\hline is exciting & 5 & 4 & 3 & 2 & 1 \\
\hline is unwelcoming & 1 & 2 & 3 & 4 & 5 \\
\hline is depressing & 1 & 2 & 3 & 4 & 5 \\
\hline has a strong sense of community & 5 & 4 & 3 & 2 & 1 \\
\hline is unattractive & 1 & 2 & 3 & 4 & 5 \\
\hline is supportive & 5 & 4 & 3 & 2 & 1 \\
\hline is unfriendly & 1 & 2 & 3 & 4 & 5 \\
\hline
\end{tabular}

